\title{
The effects of fresh leaf-to-water ratio and heating time on the antifungal and antioxidant activities of betel leaf (Piper betle L.) extract
}

\author{
Sartini Sartini $^{* 1}$, Nurdiah Khaerawati ${ }^{2}$, Rezky Amalia Kamril ${ }^{2}$, Novi Febriani ${ }^{2}$ \\ ${ }^{1}$ Department of Pharmacy, Faculty of Pharmacy, Hasanuddin University, \\ Jl.Perintis Kemeredekaan KM 10 Makassar, Sulawesi Selatan, Indonesia \\ ${ }^{2}$ Undergraduate Program, Faculty of Pharmacy, Hasanuddin University, \\ Jl.Perintis Kemeredekaan KM 10 Makassar, Sulawesi Selatan, Indonesia
}

Submitted: 02-10-2019 Reviewed: 18-11-2019 Accepted: 16-03-2020

\begin{abstract}
More than half of the Indonesian people use herbal medicines to maintain their health, including ones that are served immediately after preparation or also known as jamu gendong. This plant-based medicine is prepared traditionally by boiling using different ratios of leaves to water and heating time. The study was designed to determine the heating time and the fresh leaf-to-water ratio that exhibited the highest antioxidant and antifungal activities against Candida albicans. Fresh betel leaves were extracted by boiling and infusion methods, with the ratio of 1:5 and 1:10 and the heating time of 5 and 10 minutes for boiling and 15 minutes for infusion. The excess water in the resulting extract was removed using a freeze dryer, then the total phenolic content was determined by FolinCiocalteu spectrophotometry. Meanwhile, the antioxidant and antifungal activities were tested by the DPPH method and microdilution, respectively. The results showed that betel leaf extract with the highest yield and polyphenol content was obtained by infusion with the sample-to-water ratio of 1:10, and this was positively correlated with antioxidant activity against $\mathrm{DPPH}\left(\mathrm{IC}_{50}=17.4 \mathrm{ppm}\right)$ and antifungal effect against Candida albicans ( $\mathrm{MIC}=0.5 \%$ ).
\end{abstract}

Keywords: Piper betle L., water extract, DPPH (2,2-diphenyl-1-picrylhydrazyl), Candida albicans

\footnotetext{
*Corresponding author:

Sartini Sartini

Departement of Pharmacy, Faculty of Pharmacy, Hasanuddin University

J1.Perintis Kemeredekaan KM 10 Makassar, Sulawesi Selatan, Indonesia

Email: sardj@farmasi.unhas.ac.id
} 


\section{INTRODUCTION}

Among the Indonesian population, the leaves of betel (Piper betle L.) are known as candidiasis preventive agents. Whether for personal consumption or sale, fresh betel leaves are still processed traditionally by boiling with varying ratios of fresh leaves to water and heating time, producing a beverage called jamu gendong. This herbal remedy can be consumed on its own or combined with other traditional medicines.

According to several studies, betel leaves show antioxidant activity (Ali et al., 2018; Chauhan et al., 2016; Sarma et al., 2018), antibacterial activity against Streptococcus mutans (Thangavelu, 2013; Nalina and Rahim, 2007; Rahim and Thurairajah, 2011), and antifungal activity against Candida albicans (Ali et al., 2010). They contain bioactive components, such as hydroxychavicol, eugenol, isoeugenol, and allyl pyrocatechol 3,4-diacetate (Ali et al., 2018). Temperature and extraction time reportedly affect the resulting extract (Muruganandam et al., 2017). For instance, Soxhlet extraction typically produces ethanol extracts containing hydroxy-chavicol (69.46\%), 4-Chromanol (24\%), and eugenol (4.86\%). Meanwhile, drying at $80^{\circ} \mathrm{C}$ can cause the main components of the betel leaf to undergo decomposition, and the yield of extraction using water multiplies as temperature and leaf-towater ratio increase (Pin et al., 2006).

This study has examined the effects of heating time and the ratio of fresh betel leaves to water on the total phenolic content, antioxidant activity, and anti-candidiasis activity of betel leaf-based remedies. The result of this study can be applied to the traditional processing of betel leaves in society or by jamu gendong vendors.

\section{MATERIALS AND METHODS \\ Equipment and materials}

The research materials were Piper betle leaves (collected from a market in Makassar), distilled water, 2,2-diphenyl-1-picrylhydrazyl (Sigma), Potato Dextrose Broth (Merck), Candida albicans ATCC 10231, Folin-Ciocalteu reagent (Merck), gallic acid (Sigma). Meanwhile, the equipment used included infusion pan, incubator (Memmert), Microplate reader (BioTek), and biosafety cabinet.

\section{Methods}

\section{Extraction of betel leaves}

Fresh betel leaves that had been initially sorted were cut into small sizes of $1-2 \mathrm{~cm}^{2}$. These leaves were then extracted using the leaf-to-water ratio of 1:5 and 1:10, and each sample was boiled for 5 and 10 minutes and infused at $90^{\circ} \mathrm{C}$ for 15 minutes. The extracts obtained were lyophilized, and the yields were calculated.

\section{Determination of total phenolic content}

The total phenolic content was analyzed according to the method proposed by Farmakope Herbal Indonesia (Kemenkes RI, 2011), with gallic acid as the standard. The extract weighing $10 \mathrm{mg}$ was dissolved in $25 \mathrm{~mL}$ of methanol. One $\mathrm{ml}$ of the solution was pipetted, added with $5 \mathrm{~mL}$ of $7.5 \%$ Folin-Ciocalteu, allowed to stand for 8 minutes, and added with $1 \% \mathrm{NaOH}$. After one hour of incubation, the mixture was measured at $\lambda=755 \mathrm{~m}$.

\section{Determination of antioxidant activity}

The antioxidant activity was determined by the DPPH method using a microplate ELISA reader. The extract was dissolved in analytical-grade methanol to obtain $100 \mathrm{ppm}$ concentration. Samples with varying volumes, namely, 10, 20,30,40,50 $\mu$ l, were placed into the well. Then, each well was added with $60 \mu \mathrm{l}$ of $40 \mathrm{mM}$ DPPH solution, and the volume was filled up to $200 \mu$ l with DPPH solution. After 30-minute incubation at room temperature, the absorbance of each sample was analyzed at $\lambda$ of $515 \mathrm{~nm}$. 
The percentage of DPPH scavenging was calculated using the formula below:

$$
\% \text { DPPH Radical Scavenging }=\left(\mathrm{A}_{\text {blank }}-\mathrm{A}_{\text {sample }}\right) / \mathrm{A}_{\text {blank }} \mathrm{x} 100 \%
$$

Meanwhile, the $\mathrm{IC}_{50}$ was computed based on the regression equation $\mathrm{y}=\mathrm{ax}+\mathrm{b}$.

\section{Determination of antifungal activity against Candida albicans}

The antifungal activity against $C$. albicans was evaluated based on the minimum inhibitory concentration (MIC) by microdilution, in which a 48-well plate containing potato dextrose broth with turbidity equivalent to $1 \%$ of the McFarland standards was incubated for 2 x 24 hours.

\section{Data Analysis}

The average yield of the extract and the total phenolic content (TPC) of the lyophilized aqueous betel leaf extract were first expressed in mean \pm SD. These data were then statistically analyzed by the Student's $t$-test, and the results were considered significant when $P<0.05$.

\section{RESULTS AND DISCUSSION}

\section{Extraction yield and total phenolic content}

This study analyzed the fresh betel leaves used commonly by the community, including jamu gendong vendors. A hundred leaves with a length of $10-15 \mathrm{~cm}$ and width in the range of 7.5 and $11 \mathrm{~cm}$ were sorted and placed on a scale. These leaves, which were averagely $232.12 \mathrm{~g}$ in weight, were then washed, drained, and cut into small sizes of $1-2 \mathrm{~cm}^{2}$. Afterward, the leaves were grouped based on treatments and the independent variable, i.e., the ratio of leaf to water (1:5 and 1:10). The extraction yield and total phenolic content of the aqueous betel leaf extract obtained by boiling (5 and 10 minutes) were compared with those produced by 15 minutes of infusion. The results of both techniques were then filtered and lyophilized, and the characteristics of the extract obtained by boiling and infusion were evaluated (Table I).

Table I. The average yield (\%) and total phenolic content (TPC) of lyophilized aqueous extract from fresh betel leaves

\begin{tabular}{ccc}
\hline Samples & $\begin{array}{c}\text { Yield (\%) of lyophilized aqueous } \\
\text { betel leaf extract }\end{array}$ & $\begin{array}{c}\text { TPC (\% w/w; in gallic acid } \\
\text { equivalent-GAE) }\end{array}$ \\
\hline A & 2.16 & $12.58 \pm 0.65$ \\
B & 2.34 & $26.49 \pm 0.56$ \\
C & 1.72 & $25.06 \pm 0.90$ \\
D & 4.72 & $26.53 \pm 0.22$ \\
E & 4.92 & $23.93 \pm 0.14$ \\
F & 9.02 & $27.28 \pm 0.22$ \\
\hline
\end{tabular}

Note:

A= Lyophilizate extracted by 5-minute boiling, with leaf-to-water ratio 1:5

$\mathrm{B}=$ Lyophilizate extracted by 10-minute boiling, with leaf-to-water ratio 1:5

$\mathrm{C}=$ Lyophilizate extracted by 15-minute infusion, with leaf-to-water ratio 1:5

$\mathrm{D}=$ Lyophilizate extracted by 5-minute boiling, with leaf-to-water ratio 1:10

$\mathrm{E}=$ Lyophilizate extracted by 10-minute boiling, with leaf-to-water ratio 1:10

$\mathrm{F}=$ Lyophilizate extracted by 15-minute infusion, with leaf-to-water ratio 1:10

Compared to $1: 5$, the 1:10 ratio created a higher yield of extract potentially due to the low or insoluble chemical components in water, indicating that a higher water volume is needed. Also, with this $1: 10$ ratio, 15 minutes of heating at $90^{\circ} \mathrm{C}$ in the infusion method resulted in higher yields. The highest phenolic content (27.28\%) was found in Sample F, which was extracted by infusion with the 
1:10 ratio. However, this result does not differ significantly from that of Sample B (extraction by 10 minutes of boiling with 1:5 ratio) and Sample D (extraction by 5 minutes of boiling, with 1:10 ratio). Among the above treatments, infusion with the leaf-to-water ratio of 1:10 provided the highest yield. Multilevel extraction of betel leaves using hexane, ethyl acetate, methanol, and water has proven that the highest total phenolic content is found in the ethyl acetate extract, followed by the hexane, methanol, and lastly water extracts (Abrahim et al., 2012). A study of the nutraceuticals properties of Piper betel (Paan) (Chauhan et al., 2016) also confirms that, in the order of highest to lowest, phenols can be found in methanol, ethanol, ethanol-water, and water extracts. Another study reports that the water extract of dried betel leaves that have been macerated for 4 hours with hot water has a total phenolic content of $128.89 \mathrm{mg} / \mathrm{g}$ extract or approximately $12.9 \% \mathrm{w} / \mathrm{w}$ (Taukoorah et al., 2016). Furthermore, boiling fresh betel leaves with the leaf-to-water ratio of 1:50 for 30 seconds produces extracts containing a total phenolic compound of $676 \mathrm{mg}$ per $100 \mathrm{~g}$ of fresh leaves $(0.68 \%)$ (Tan et al., 2014). In other words, the total phenolic content of betel leaf extract varies depending on the extraction method, the solvent used, and the leaf-to-water ratio. Despite the use of water as a solvent, this study obtained relatively high levels of phenolics. This finding is potentially caused by the manner of heating and the use of fresh leaves. The content of the hydroxy catechol in betel leaf can be increased by raising the extraction temperature to $60^{\circ} \mathrm{C}$ with an equilibrium point of 30 minutes; drying at $50-60^{\circ} \mathrm{C}$ is found to be optimum, whereas rehydration at $40^{\circ} \mathrm{C}$ is claimed to produce the best or most acceptable product (Pin et al., 2006; Balasubramanian et al., 2011).

\section{Antioxidant activity}

The in vitro test by the DPPH method revealed that the highest antioxidant activity was exhibited by Sample F (extracted by infusion with the 1:10 ratio). A smaller $\mathrm{IC}_{50}$ value can lead to a stronger antioxidant property, which is associated with total phenolic compounds. Sample F showed a relatively high total phenolic level, and the lowest $\mathrm{IC}_{50}$ value against $\mathrm{DPPH}$ was compared to the other samples.

Table II. The $\mathrm{IC}_{50}$ of the lyophilized aqueous extract of fresh betel leaves against DPPH $\mathrm{IC}_{50}(\mu \mathrm{g} / \mathrm{mL})$ against DPPH

\begin{tabular}{ccccccc}
\cline { 2 - 7 } Samples & A & B & C & D & E & F \\
\hline Average & 40.63 & 23.36 & 22.24 & 18.54 & 19.97 & 17.14 \\
\hline
\end{tabular}

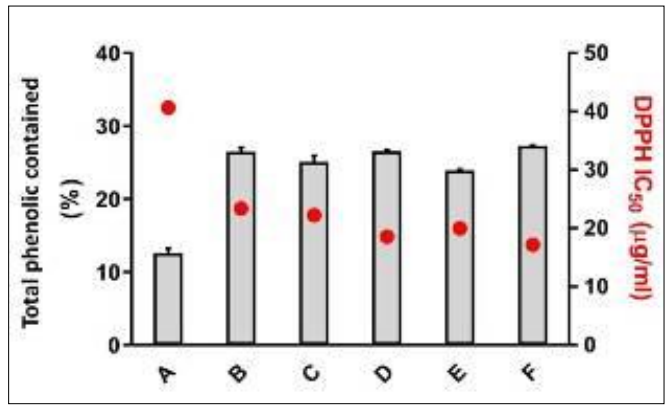

Figure 1. Histogram of the correlation between the total phenolic content (\%) and the $\mathrm{IC}_{50}$ against DPPH based on the test samples

Several studies have also confirmed the high antioxidant activity of betel leaf extract. For instance, betel leaves are found to exhibit antioxidant activity with the $\mathrm{IC}_{50}$ of $179.5 \pm 93.1 \mathrm{ppm}$ against DPPH (Nur Sazwi et al., 2013), and the water extract of a selected variety of betel leaves 
indicates antioxidant effects against DPPH (Sharma et al., 2010). Furthermore, betel leaf extract has a proton-donating ability and can serve as a free radical inhibitor or scavenger (Umar et al., 2018).

\section{Minimum inhibitory concentration (MIC)}

Based on the results of the antifungal activity test against $C$. albicans (microdilution), the lyophilized aqueous betel leaf extract has the MIC of 0.5\%-1\%, as shown in Table III and Figure 2.

Table III. The MIC values (\%) of the lyophilized aqueous extract of fresh betel leaves MIC values (\%) of the lyophilizates of the fresh betel leaf extract

\begin{tabular}{ccccccc}
\cline { 2 - 6 } Sample & $\mathrm{A}$ & $\mathrm{B}$ & $\mathrm{C}$ & $\mathrm{D}$ & $\mathrm{E}$ & $\mathrm{F}$ \\
\cline { 2 - 7 } & 1 & 1 & 1 & 0.5 & 0.5 & 0.5 \\
\hline
\end{tabular}
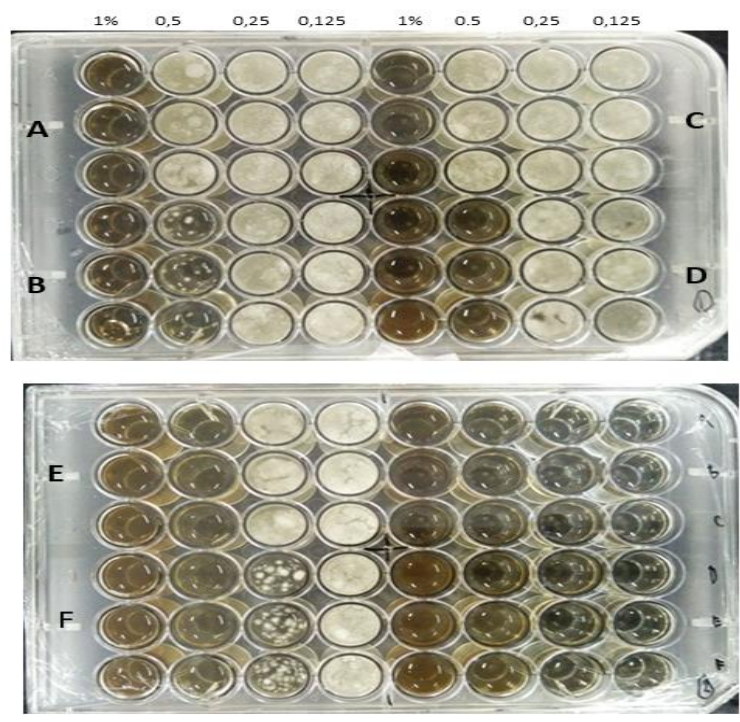

Figure 2. Determination of minimum inhibitory concentration by microdilution (Mueller-Hinton broth media, incubation time at $37^{\circ} \mathrm{C}$ for 48 hours)

Boiling and infusion using the leaf-to-water ratio of 1:10 exhibited higher antifungal activities against Candida albicans, with the MIC of $0.5 \%$ (Figure 2 and Table III). Although, Sample F (infusion with a 1:10 ratio) has the same MIC as Samples D and E, at a concentration of $0.25 \%$, the growth of C. albicans in Samples D and E was higher than in Sample F (Figure 2); therefore, this study recommends infusion for optimal fresh betel leaf extraction. On the other hand, boiling dried betel leaves using distilled water with the leaf-to-water ratio of 1:10 for 5-6 hours produces extracts with a higher MIC, that is, $12 \mathrm{mg} / \mathrm{mL}$ (1.2\%) (Himratul-Aznita et al., 2011). Ali et al. (2010) suggest that hydroxychavicol isolated from aqueous betel leaf extracts inhibit the biofilm formation by several Candida albicans isolates, with an MIC of around 125-500 ppm.

\section{CONCLUSION}

With 1:10 leaf-to-water ratio and 15 minutes of heating, extraction by infusion produces betel leaf extracts that have the highest antioxidant and antifungal activities against Candida albicans. 


\section{RECOMMENDATION}

Because aqueous betel leaf extract has been proven to have a strong antioxidant activity against $\mathrm{DPPH}\left(\mathrm{IC}_{50} 17.14 \mathrm{ppm}\right)$, it is recommended as an anti-tumor candidate in cell lines or anti-aging materials and as a gel dosage form for oral mucosal candidiasis in future research.

\section{ACKNOWLEDGMENT}

This research was funded by the internal research funding of UNHAS, namely Academic Assistant Lecturer Research Grant, with the contract number 2319 - UN4 / KU / 02.01 / 2019.

\section{REFERENCES}

Abrahim, N.N., Kanthimathi, M.S., Abdul-aziz, A., 2012, Piper betle shows antioxidant activities, inhibits MCF-7 cell proliferation and increases activities of catalase and superoxide dismutase, BMC Complementary Medicine and Therapies, 12(220): 1-12.

Adawiyah Umar, R., Sanusi, A., Nizam Zahary, M., Adzim Khalili Rohin, M., Ismail, S., 2018, Chemical composition and the potential biological activities of piper betel-A Review, Malaysian Journal of Applied Sciences, 3(1): 1-8.

Ali, A., Lim, X.Y., Chong, C.H., Mah, S.H., Chua, B.L., 2018, Ultrasound-assisted extraction of natural antioxidants from betel leaves (Piper betle): Extraction kinetics and modeling. Separation Science and Technology, 53(14) : 2192-2205.

Ali, I., Khan, F.G., Suri, K.A., Gupta, B.D., Satti, N.K., et al., 2010, In vitro antifungal activity of hydroxychavicol isolated from Piper betle L, Ann Clin Microbiol Antimicrob, 9(7): 1-9.

Balasubramanian, S., Sharma, R., Gupta, R.K., Patil, R.T., 2011, Validation of drying models and rehydration characteristics of betel (Piper betle L.) leaves, Journal of Food Science and Technology, 48: 685-691.

Chauhan, E.S., Aishwarya, J., Singh, A., Tiwari, A., 2016, A Review: Nutraceuticals Properties of Piper betel (Paan), American Journal Phytomedicine and Clinical Therapeutics, 4(2): 028-041.

Himratul-Aznita, W.H., Mohd-Al-Faisal, N., Fathilah, A.R., 2011, Determination of the percentage inhibition of diameter growth (PIDG) of piper betle crude aqueous extract against oral Candida species, Journal of Medical Plants Research, 5(6) : 878-884.

Kementrian Kesehatan RI., 2011. Suplemen II Farmakope Herbal Indonesia Edisi 1.

Muruganandam, L., Krishna, A., Reddy, J., Nirmala, G.S., 2017, Resource-efficient technologies optimization studies on extraction of phytocomponents from betel leaves. Resource-Efficient Technologies, 3(4): 385-393.

Nalina, T., Rahim, Z.H.A., 2007, The crude aqueous extract of Piper betle L. and its antibacterial effect towards Streptococcus mutans, American Journal of Biochemistry and Biotechnology. 3(1): 10-15.

Nur Sazwi, N., Nalina, T., Rahim, Z.H.A., 2013, Antioxidant and cytoprotective activities of Piper betle, Areca catechu, Uncaria gambir and betel quid with and without calcium hydroxide. $B M C$ Complementary Alternative Medicine, 13(351): 1-12.

Pin, K.Y., Chuah, T.G., Rashih, A.A., Rasadah, M.A., Law, C.L., Choong, T.S.Y., 2006, Aqueous Extraction of Hydroxychavicol from Piper Betle L. Leaves, Proceedings of the $1_{\text {st }}$ International Conference on Natural Resources Engineering \& Technology, 146-152.

Rahim, Z.H.A., Thurairajah, N., 2011, Scanning electron microscopic study of Piper betle L. leaves extract effect against Streptococcus mutans ATCC 25175, Journal of Applied Oral Science, 19(2), 137-146.

Sarma, C., Rasane, P., Kaur, S., Singh, Jyoti, Singh, Joginder, Gat, Y., Garba, U., Kaur, D., Dhawan, K., 2018, Antioxidant and antimicrobial potential of selected varieties of piper betle L. (Betel leaf). Anais da Academia Brasileira de Ciencias, 90(4): 3871-3878.

Sharma, S., Kumar, M., Sharma, S, Nargotra, A., Koul, S., Khan, I.A., 2010, Piperine as an inhibitor of Rv1258c, a putative multidrug efflux pump of Mycobacterium tuberculosis, Journal of 
Antimicrobal Chemotherapy, 65(8): 1694-1701.

Tan, Y.P., Wei, E., Chan, C., 2014, Antioxidant, antityrosinase and antibacterial properties of fresh and processed leaves of Anacardium occidentale and Piper betle, Food Bioscience, 6: 17-23.

Taukoorah, U., Lall, N., Mahomoodally, F., 2016, South African Journal of Botany Piper betle L.

(betel quid ) shows bacteriostatic, additive, and synergistic antimicrobial action when combined with conventional antibiotics, South African Journal of Botany, 105: 133-140.

Thangavelu, T., 2013, Antibacterial effect of crude aqueous extract of Piper betle L. against pathogenic bacteria, International Journal Research in Pharmaceutical and Biomedical Sciences, 4(1): 42-46. 
